\title{
Comparative study of safety and efficacy of electrocautery blade with cold scalpel blade for skin opening during fixation of fracture of forearm bone with plate and screws
}

\author{
RP Shah Kalawar, GP Khanal, P Chaudhary, R Rijal, R Maharjan, SR Paneru, B Pokharel \\ Department of Orthopaedics, B.P. Koirala Institute of Health Sciences, Dharan, Nepal
}

\begin{abstract}
Background: Skin incisions have usually been made using a scalpel. Electrocautery, a more recent alternative, is thought to increase the risk of infection, impair healing and decrease cosmesis. Recent studies suggest that electrocautery may offer potential advantages with respect to blood loss, incision time and postoperative pain. Objective: The aim of this study was to compare the efficacy and safety of electrocautery incisions versus conventional scalpel incisions in orthopedic surgeries using internal implants. Method: The study was conducted as a prospective one in a tertiary care center in the Department of Orthopaedics, BPKIHS, Dharan, Nepal. Patients with closed fracture of the forearm bones admitted for surgery from April 2014 to September 2014 was included in the study. Each incision was divided into two halves, proximal half to be opened by steel scalpel blades and the distal half to be opened by an electrocautery blade. Proximal half and distal half of incision were compared on operating day and on days 2 , 14 and again on 6 weeks and 3 month. Result: A total of 60 patients were enrolled in the study. Forearm skin incisions using electrocautery were significantly quicker than scalpel incisions $(p<0.05)$. Postoperative wound complication rates did not differ significantly between the Scalpel and Electrocautery groups $(p>0.05)$. Conclusion: There is no difference in healing of two halves of skin incision made by electrocautery and scalpel in orthopedic surgeries using internal implants.
\end{abstract}

Key words: Electrocautery, skin incision, scalpel

\section{Introduction}

The art of performing surgeries have

\section{Address for correspondence}

Rosan Shah Kalawar

Department of Orthopaedics

B.P. Koirala Institute of Health Sciences, Dharan

Email: docrosan@yahoo.com improved in recent years with the development of various electrosurgical devices assisting surgeons in performing safer surgeries with better outcomes. Skin incision has traditionally been made with a standard scalpel blade with good primary 
healing end results of the wound. The electrocautery has been used safely in performing deeper dissections. Use of electrocautery in skin incision has been discouraged in the past for the fear of cutaneous scarring, wound dehiscence, and infections particularly in orthopedic surgeries using internal implants.

Recently, use of electrocautery has been shown to offer many advantages 1-6 including time, safety and healing, yet still it is being debated. Therefore the present study aimed to determine whether an electrocautery blade can be used safely for skin incisions in limb surgeries.

\section{Methods}

The study was conducted as a prospective one in a tertiary care center in the department of orthopaedics, BPKIHS, Dharan, Nepal. Patients with closed fracture of the forearm bones admitted for surgery from April 2014 to September 2014 was included into the study. The operating theatre records of 2013 showed that the number of cases of forearm bones fracture operated from 1st April to 30th September was 66. Arbitrarily it was decided to take 60 of cases. Ethical clearance was obtained before the study from Institute Ethical Review Board and informed consent was taken from each patient involved in the study. The following patients were excluded from study:
- Open fractures,

- Previous history of hypertrophic or keloid scarring,

- Patients suffering from chronic immunosuppressive disorders or wound healing problems,

- Patients on long-term medications, which interferes with wound healing, such as corticosteroids, anticancer drugs, or colchicines for gout.

The patients were given numerical codes in sequence. All surgeries were performed under general/regional anesthesia with use of tourniquets. The incision site was marked. Each incision was then divided into two halves, proximal half to be opened by steel scalpel blades and the distal half to be opened by an electrocautery blade [figure 1a]. The electrocautery unit was set on cutting pure mode, at a power of $5 \mathrm{~W}$ and using a $390-\mathrm{kHz}$ sinusoid waveform during the procedure.

The incision depth included the epidermis, dermis, and the superficial part of the subcutaneous layer. During electrocautery incision, only the tip of the blade was allowed to come in contact with the proposed incision line and care was taken not to touch the skin edges with the sides of the electrocautery blade at any time by applying mild traction on either sides of the skin incision as the cutting proceeded. 
The floor nurse noted the time taken to complete the incision on each side separately using a stop clock. The length of each half of the incision was recorded. The speed of skin incision was calculated in $\mathrm{mm} / \mathrm{s}$ from the start of incision until completion of the incision, including hemostasis. The speed of incision was calculated by dividing length in millimeters by time in seconds for each half separately. The time calculated for incision did not include deep fascia or periosteum opening.
On completing total skin incision, the wound edges were inspected for any physical differences between the parts performed by the electrocautery and cold scalpel [Figure 1b]. The incision wound with scalpel and electrocautery was inspected in each case immediately after completing the skin incision with respect to color, viability, presence of charring effect, and dermal peeling by naked eye examination.
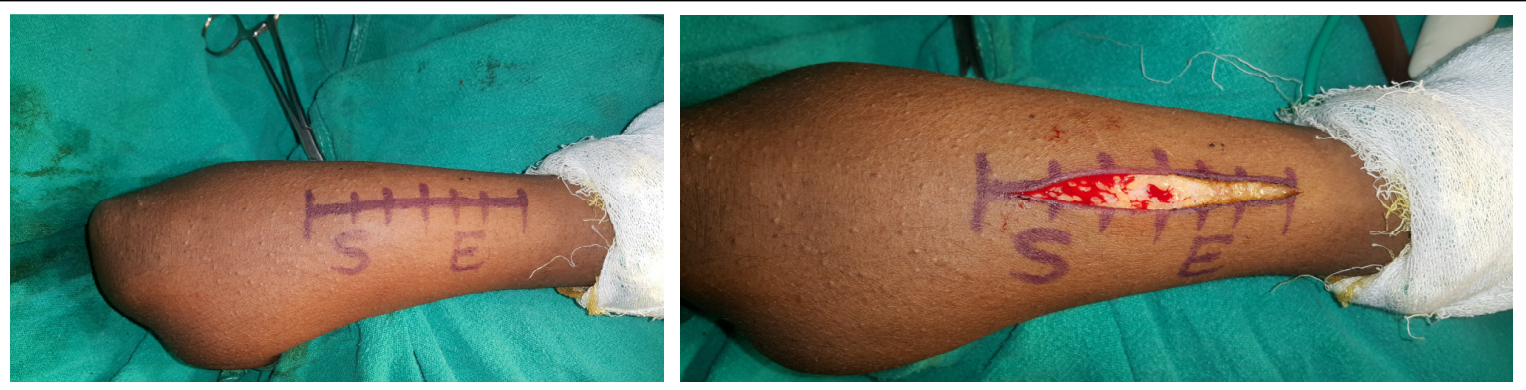

Figure 1a: Skin incision marked and divided into proximal half to be opened by scalpel (S) and distal half to be opened by Electrocautery; 1b: Macroscopic appearance of the wound on completing skin

Deeper dissection was continued as usual and fractures was fixed with a $3.5 \mathrm{~mm}$ lowcontact dynamic compression plate in each case. The wound was closed in layers using nylon or staples for the skin. The fascia was not closed to decrease the chance of compartment syndrome if any. The wound was inspected on postoperative days 2, 14 and at 6-weeks post-operative follow-up. The variables evaluated in this study was time taken for incision; differences with respect to physical inspection of the wound edges soon after incision; cosmetic appearance of the scar as good, poor, contracted; and formation of keloids and wound complications.

\section{Results}

Sixty incisions were performed using a cold scalpel and electrocautery blade in open reduction and internal fixation of the fracture of the shaft of the radius and/or ulna using a low-contact dynamic compression plate.

The speed of incision when a cold scalpel was used ranged between $0.65 \mathrm{~mm} / \mathrm{s}$ and 2.1 
$\mathrm{mm} / \mathrm{s}$, with an average of $1.0 \mathrm{~mm} / \mathrm{s}$. The speed of incision with electrocautery blade was between $1.2 \mathrm{~mm} / \mathrm{s}$ and $2.9 \mathrm{~mm} / \mathrm{s}$, with an average of $1.8 \mathrm{~mm} / \mathrm{s}$. The average time taken by electrocautery for performing a $10 \mathrm{~cm}$ skin incision was $1 \mathrm{~min}$ against $2 \mathrm{~min}$ by cold scalpel. The time taken for incision with electrocautery was much lower in comparison with the cold scalpel.

There were no macroscopic differences with respect to color, viability, presence of charring effect, and dermal peeling between cold scalpel and electrocautery incisions. Postoperative inspection on days 2 and 14 also did not have any differences in the physical character of the wound [Figure 2a]. Healing of skin wound incised with cold scalpel and electrocautery at the end of 6 weeks and 3 months were the same [Figure $2 b]$. There were no differences in scar tenderness on either half of the incision made by cold scalpel and electrocautery at 3 months follow up.

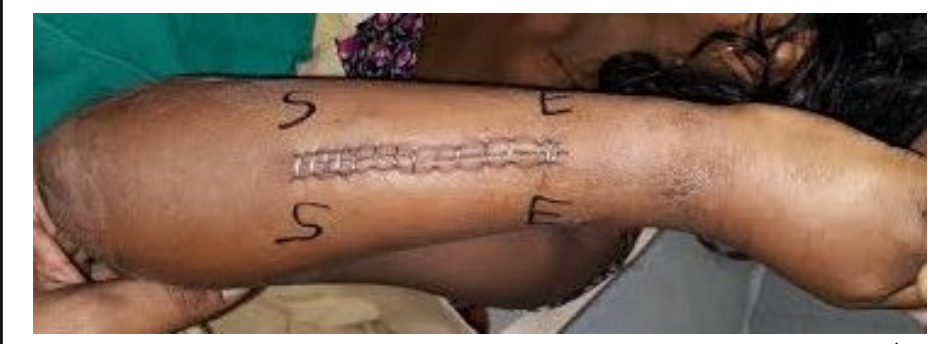

Figure 2a: Macroscopic appearance of the wound on $2^{\text {nd }}$ week follow up and 2b: on 6 month follow up.

Because of the tourniquet application, blood loss with these two methods of incision could not be evaluated.

Two (3.3\%) cases of superficial stitch abscess were found involving the full length of the skin incision, which was effectively managed with antibiotics and regular dressings.

There was no evidence of scar tenderness, hypertrophy, or keloid formation of the scar, or wound dehiscence either with cold scalpel or electrocautery incision in 3 month follow up.

\section{Discussion}

Surgical electrocautery has increasingly been used for tissue dissection, being haemostatic and convenient, since beginning of the $20^{\text {th }}$ century when it was first introduced ${ }^{7-9}$. Surgeons, however, continue to be reluctant when it comes to the use of electrocautery for making an incision of $\operatorname{skin}^{9,10,11}$ because 
previous studies has shown that the use of electrocautery causes devitalization of tissue within the wound which consequently lead to wound infection, delayed wound healing and excessive scarring ${ }^{9,10,12,13}$. Despite this evidence in these randomized clinical trials in support of electrocautery use in making skin incisions, many surgeons in many centers including our centre still are reluctant to use electrocautery in making skin incisions ${ }^{10,11}$. So this study was aimed at investigating this alternative method of incision with comparison to the scalpel incision with regards to advantages, like time and bleeding, as well as alleged complication like wound infection.

There are conflicting results in human studies. It has been reported in Soballe et $\mathrm{al}^{14}$ study that electric coagulation increases the incidence of indurated margins, infections, and weakness of the wound cut in comparison with the knife. Conversely, Groot et $\mathrm{al}^{15}$ reported that use of surgical electrocautery to create surgical wounds in patients undergoing abdominal or thoracic operations carries a wound infection rate similar to that of scalpel.

Our present study shows electrocautery incision is better than scalpel incision in terms of time taken for incision, and no significant difference in terms of wound healing, post operative complication rate and in length of hospital stay in open reduction and internal fixation of the fracture of the shaft of the radius and/or ulna using a low-contact dynamic compression plate. Blood loss could not be compared due to use of tourniquet.

The fear of tissue injury and wound complication in electrocautery incision was first unfolded when this technique was used by Peterson ${ }^{16}$ in reconstructive and cosmetic faciomaxillary surgery, Tobin $^{17}$ in blepheroplasty, with minimum scarring and excellent results.

Kearns et $\mathrm{al}^{12}$ who compared electrosurgical and scalpel methods in hundred patients undergoing elective midline incision have found that the diathermy incision has significant advantages over scalpel incision based on incision time, blood loss, early postoperative pain and analgesia requirements. There was no significant difference in terms of wound complications, including wound infection, as reported by the present study.

The present study showed no statistically significant differences in the rate of postoperative complications and postoperative hospital stay which is in consistent with other trials ${ }^{9,12}$. On the basis of this study, it is suggested that skin may be safely incised using electrocautery in limb surgery involving fixation of bones using internal implants. 


\section{Conclusion}

We conclude that skin may be safely and rapidly incised using electrocautery in limb surgery involving fixation of bones using internal implants with as good wound healing characteristics as that of with cold scalpel.

\section{References}

1. Kearns SR, Connolly EM, McNally S, McNamara DA, Deasy J. Randomized clinical trial of diathermy versus scalpel incision in elective midline laparotomy. Br J Surg 2001; 88:41-4.

2. Sheikh B. Safety and efficacy of electrocautery utilization for skin opening in neurosurgery. $\mathrm{Br} J$ Neurosurg 2004; 18:268-72.

3. Chrysos E, Athanasakis E, Antonakakis S, Xynos E, Zoras O. A prospective study comparing diathermy and scalpel incisions in tension-free inguinal hernioplasty. Am Surg. 2005; 71(4)(71(4)): 326-9.

4. Byrne FJ, Kearns SR, Mulhall KJ, McCabe JP, Kaar K, Gilmore M, O'Sullivan M, Curtin W. Diathermy versus scalpel incisions for hemiarthroplasty for hip fracture: a randomised prospective trial. Eur $\mathrm{J}$ Orthop Surg Traumatol. 2007; Jul; 25.

5. Shamim M. Diathermy vs scalpel skin incisions in general surgery: Double- blind, randomized, clinical trial. World J Surg 2009; 33:1594-9.

6. Chalya PL, Mchembe MD, Mabula JB, Gilyoma JM. Diathermy versus Scalpel incision in elective midline laparotomy: A prospective randomized controlled clinical study. http://www.ajol.info/index.php/ecajs/artic le/viewFile/89927/79380. 2015; 21: 5255

7. Cushing $\mathrm{H}$. Electrosurgery as an aid to the removal of intracranial tumors with a preliminary note on a new surgical current generator. Surg Gynecol Obstet 1989, 64:47:751-84.

8. Leaper DJ. Basic surgical skills and anastomosis. In: Russell RC, Williams NS, Bulstrode CJ. Editors. Bailey and Love's Short Practice of Surgery. 24th ed. London. Arnold; 2004, 95-106.

9. Siraj A, Farooq-Dar M, Gilani AB, Raziq S. Elective midline laparotomy: Comparison of diathermy and scalpel incisions. Professional Med J. 2011, 18(1): 106-111

10. Kumar V, Tewari M, Shukla HS. A comparative study of scalpel and surgical diathermy incision in elective operations of head and neck cancer. Indian J Cancer 2011, 48:216- 9

11. Lodhi FB, Asrar R, Akram M, Hussain R. Incidence of Abdominal Wound Dehiscence (Midline Vs Paramedian 
Incision Closed With Vicryl No.1). King Edward med Coll 2001, 7:38-40

12. Kearns SR, Connolly EM, McNally S, McNamara DA, Deasy J. Randomized clinical trial of diathermy versus Scalpel incision in elective midline laparotomy. Br J Surg 2001, 88:41-4.

13. Ly J, Mittal A, Windsor J. Systematic review and meta-analysis of cutting diathermy versus scalpel for skin incision. Br J Surg, 2012, 99: 613-620.

14. Soballe PW, Nimbkar NV, Hayward I. Electric cautery lowers the contamination threshold for infection of laparotomies. Am J Surg 1998, 175:263-6

15. Groot G, Chappell EW. Electrocautery used to create incisions does not increase wound infection rates. Am J Surg 1994, 167:601-603

16. Peterson A. The use of electrosurgery in reconstructive and cosmetic maxillofacial surgery. Dental Clin North Am .1982, 20:799-823.

17. Tobin HA. Electrosurgical blepheroplasty: A technique that questions conventional concepts of fat compartmentisation. Ann Plastic Surg 1985, 14: 59-63. 